\title{
الإشتراك اللفظى فى اللغة العربية
}

Khaerun Nisa Nuur

hjnisa82@gmail.com

جامعة علاء الدين الإسلامية الحكومبية

\begin{abstract}
Abstrak
Artikel ini mereupakan hasil penelitian tentang pola homonim dalam bahasa Arab. Penelitian ini adalah library researche (penelitian kepustakaan) yang pengumpulan datanya dilakukan sepenuhnya dengan membaca buku-buku terkait. Metode-metode yang dilakukan adalah metode deduktif, induktif dan perbandingan. Penelitian ini menunjukkan bahwa homonym dalam Bahasa Arab mengandung keindahan Bahasa. Keindahan itu tercermin dalam eksistensinya dalam bahasa Arab tetapi penggunaannya terbatas termasuk dalam buku-buku linguisik klasik, hal ini tidak seperti penggunaannya dalam Bahasa Indonesia dan bahasa Inggris. Kemungkinan perkembangan homonym dalam Bahasa Arab juga diperselisikan oleh para bahasa.
\end{abstract}

\section{التجريل}

هذا المقالة تقصد البحث عن صيغة الإشتراك اللفظى في اللغة

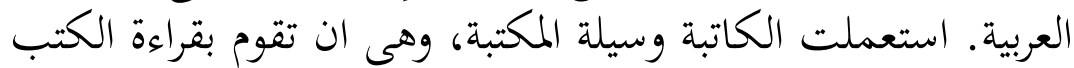

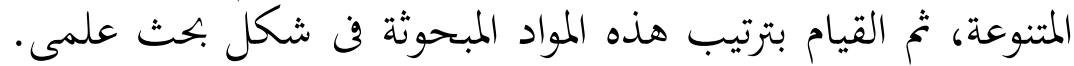

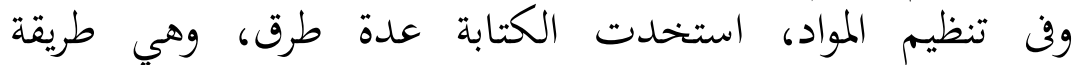

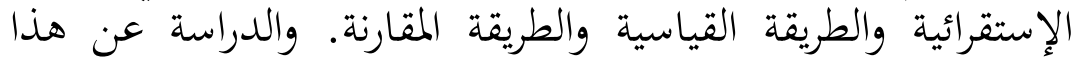

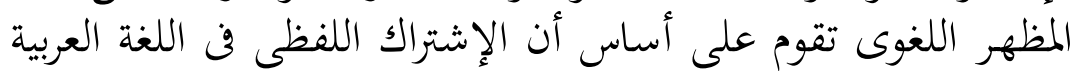

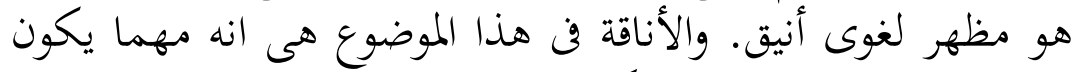

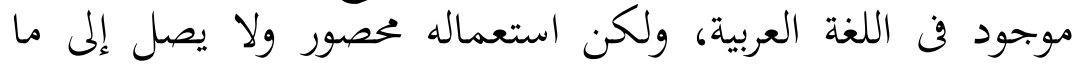

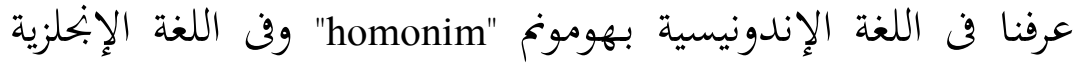

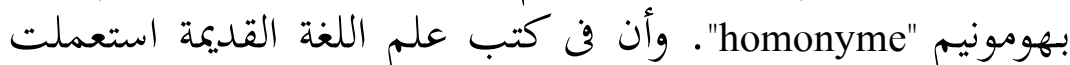

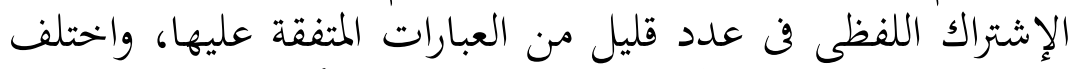
بعض علماء اللغة في امكانيات تطوير هذه المسألة في اللغة العربية. 


\section{أ. مقلدمة}

إن اللغة العربية أوسع اللغات استعمالا في العالم، وهى اللغة الوحيدة بين اللغات

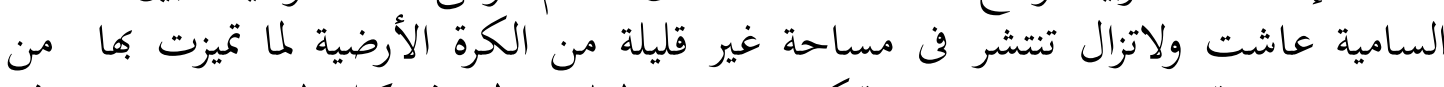

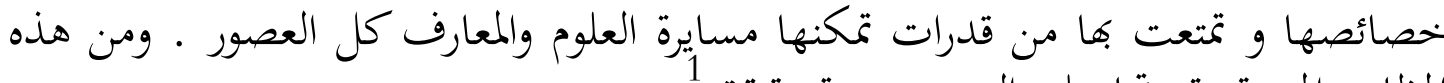

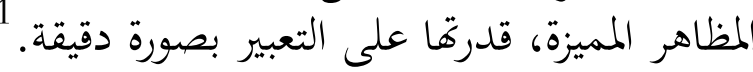

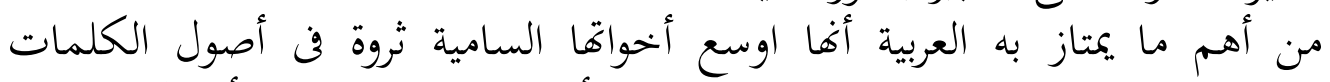

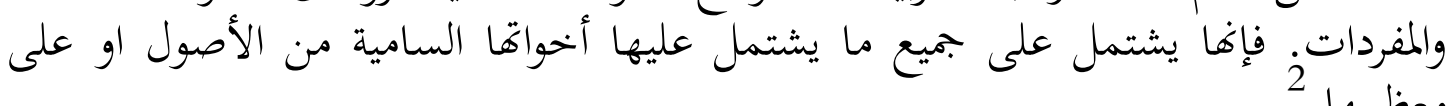

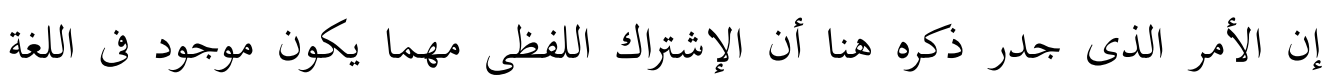

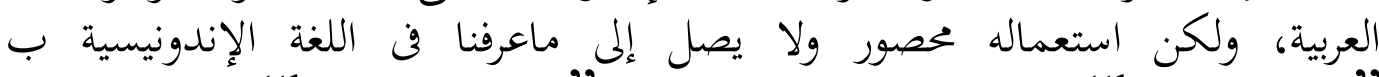

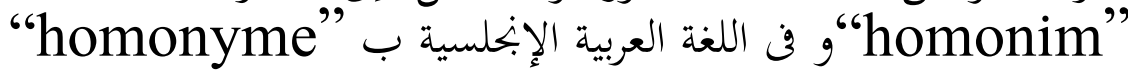

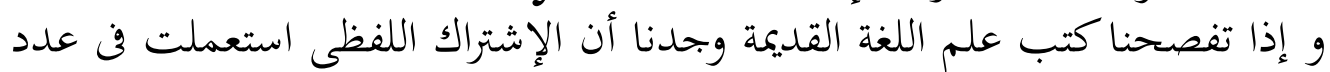

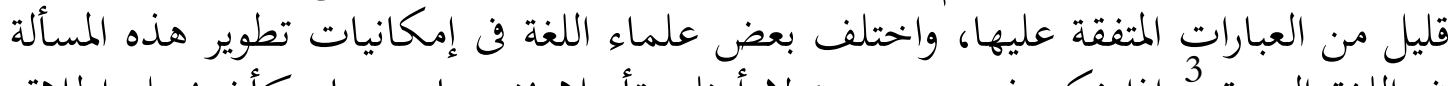

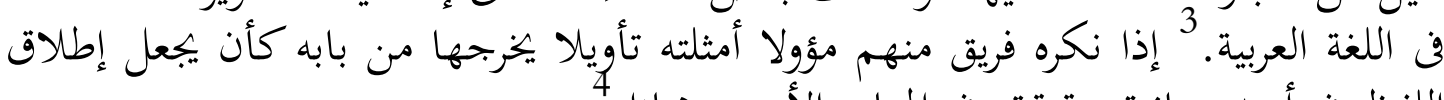

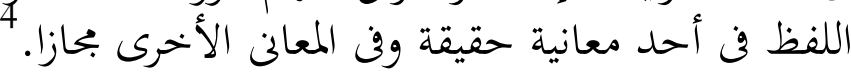

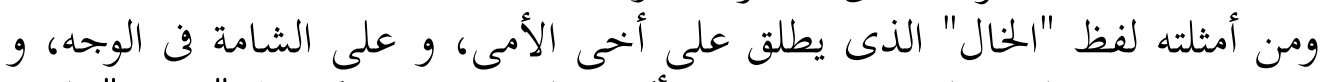

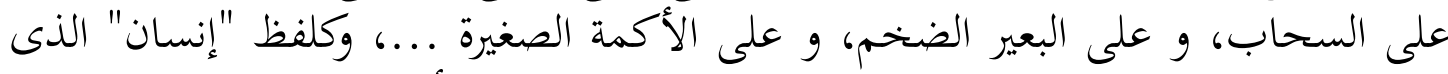

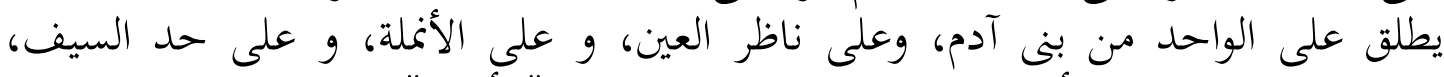

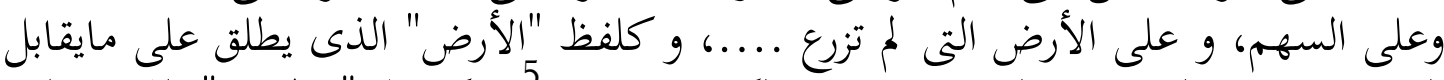

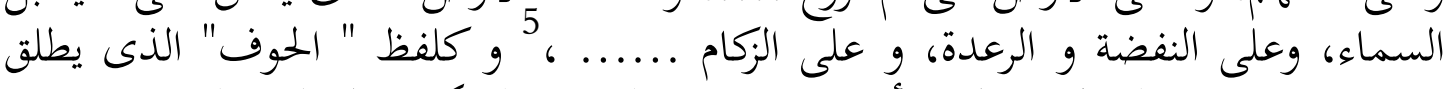

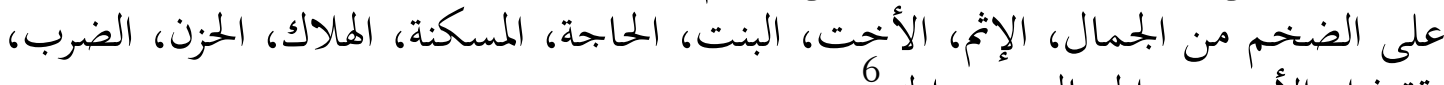

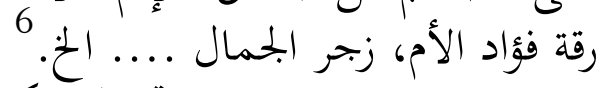
إعتماداعما ذكرناه سابقا، تحاول اللحال الكاتبة أن تعرض مشكالات لتحات لتجعلها نقطة الإنطلاق في كتابة بحثها كما يلي :

$$
\text { 1 صبحى الصاخ، دراسات فن فقه اللغة، (البيروت : المكتبة الأهلية، 1962)، ص:117. }
$$

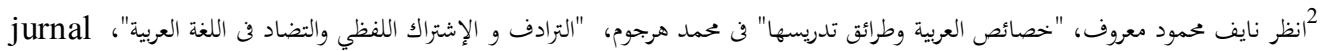

252 . Adabiyah. Vol. X Nomor 2/2010.

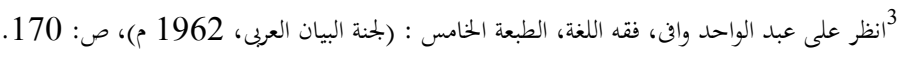

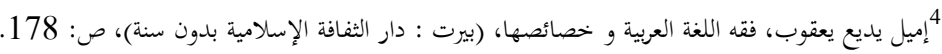

$$
\begin{aligned}
& \text { كلعلى عبد الواحد وافى، فقه اللغة ، ص:183. }
\end{aligned}
$$

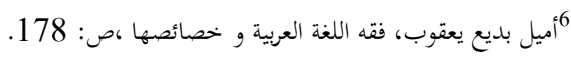




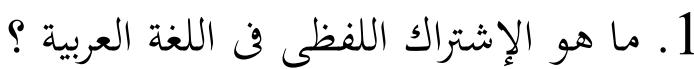

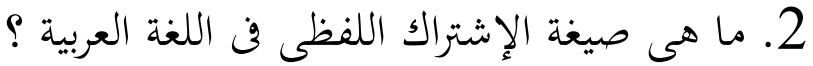

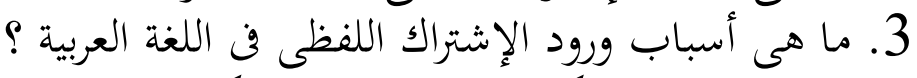

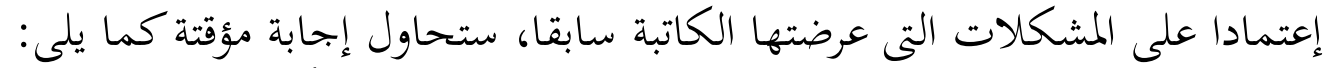

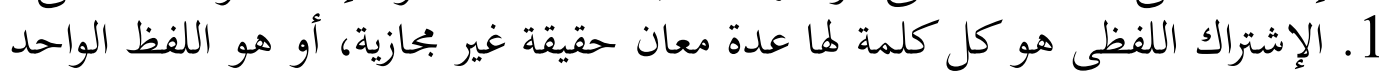

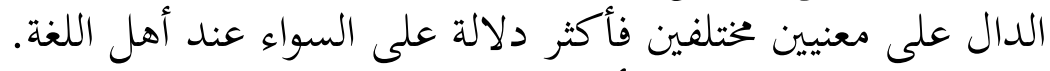

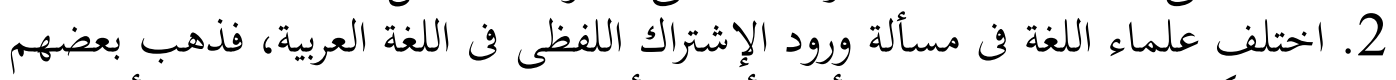

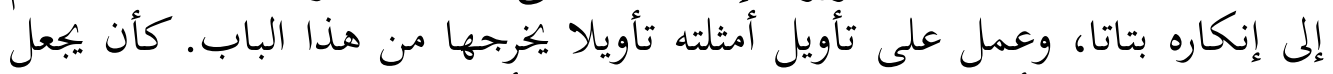

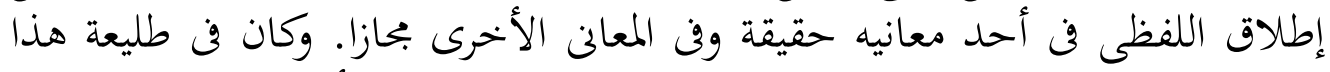

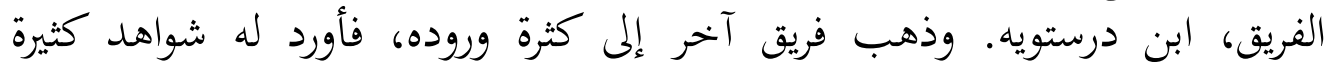

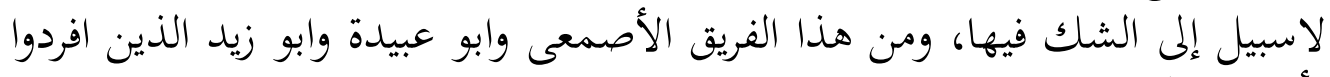

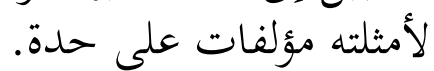

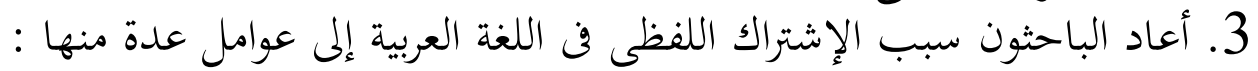

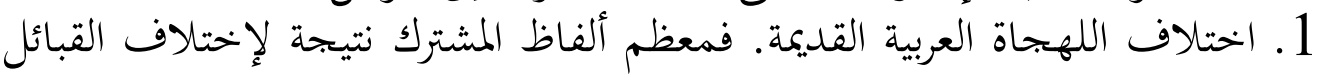
في استعملها. 2. التطور الصوتى الذى يطرأ على بعض أصوات اللفظ الأصلية من حذف اوزيادة، أوإبدال.

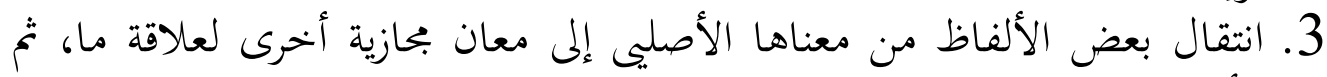

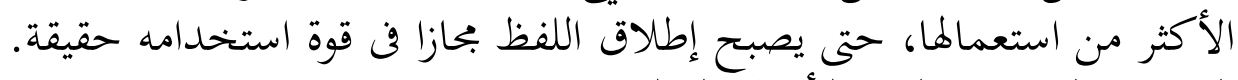

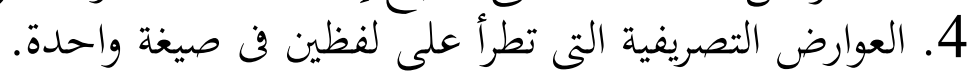

\section{ب. التعريف بالإشتراك اللفظى}

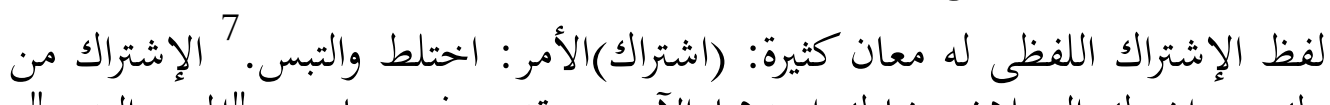

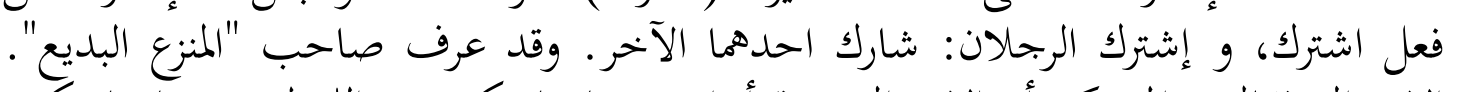

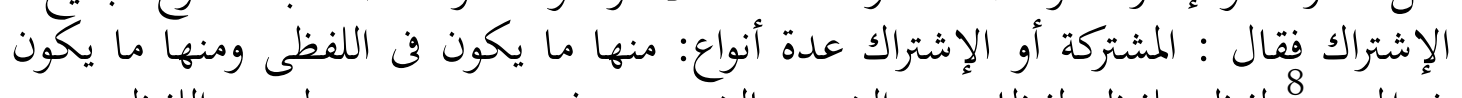

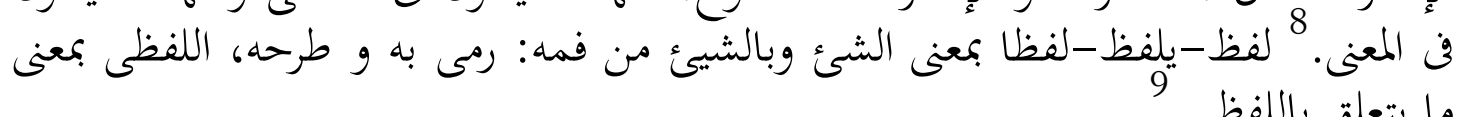
ما يتعلق باللفظى المعنى.

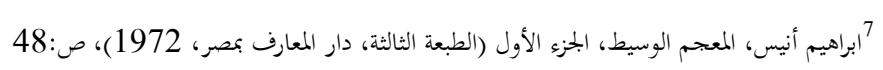

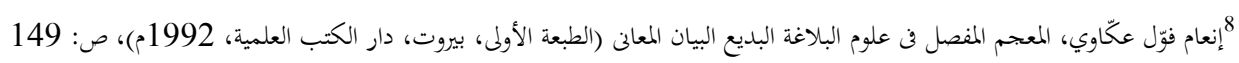

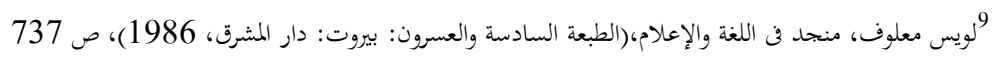




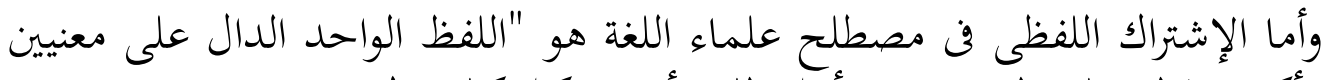

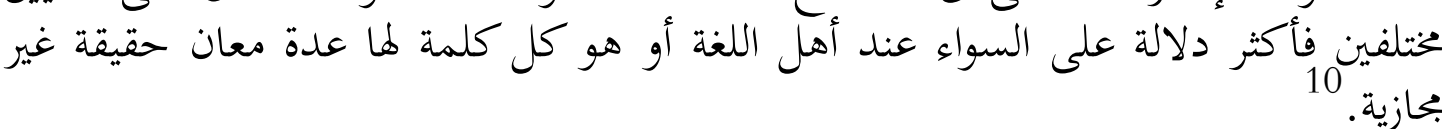

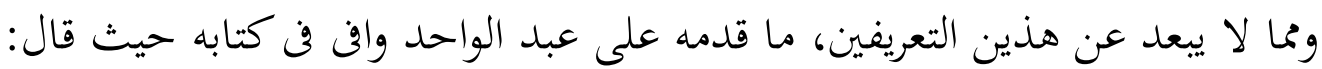

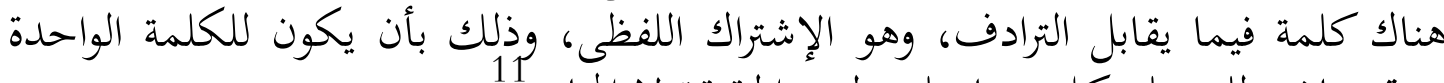

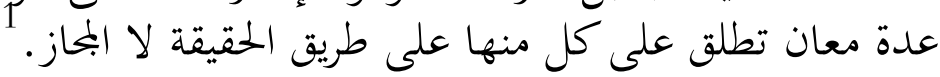

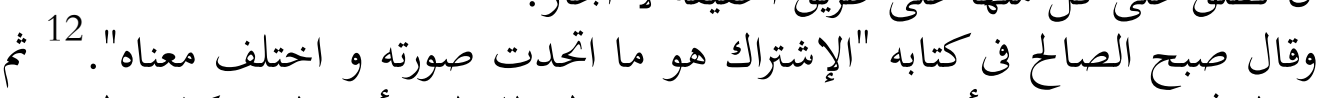

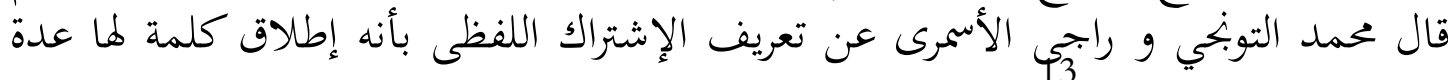
معان حقيقة غير بحازية. اعتماد على التعريفات المتقدمة نعريف أن الإشتراك اللفظى هو مظاهر من لغوية وهو إطلاق كلمة على عدة معان.

\section{ج. خصائص الإشتراك اللغظى فى اللغة العربية و مواقعها}

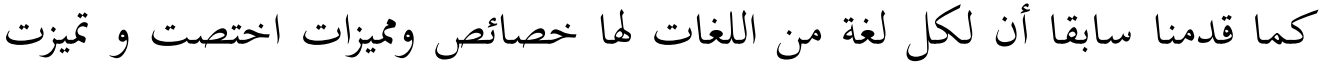

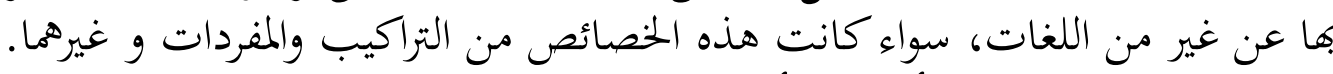

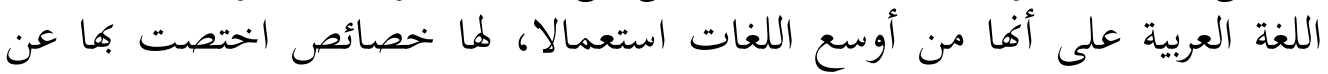

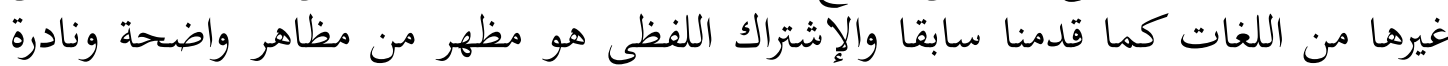

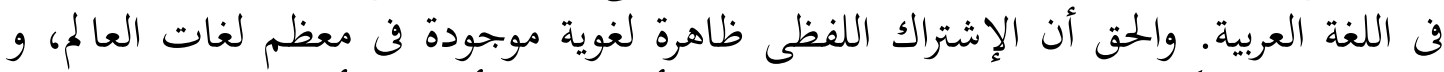

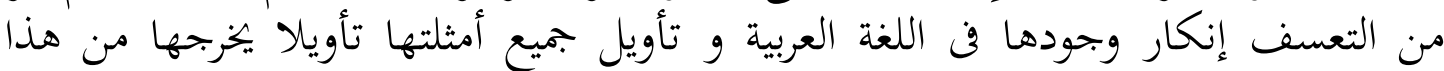

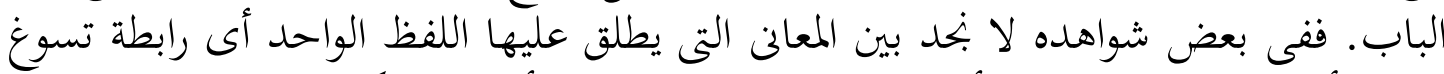

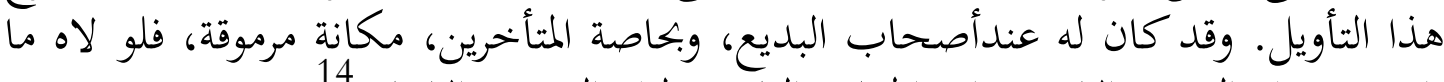

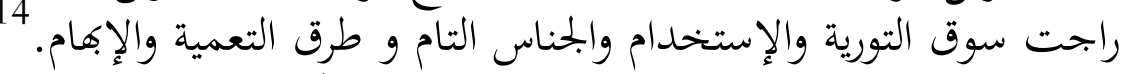

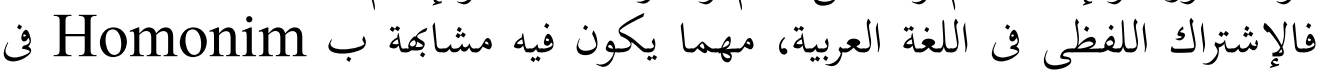

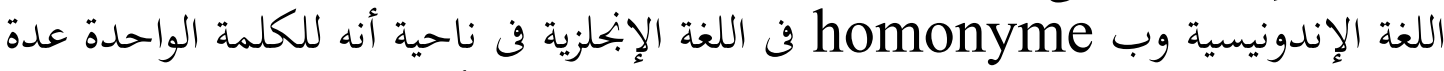

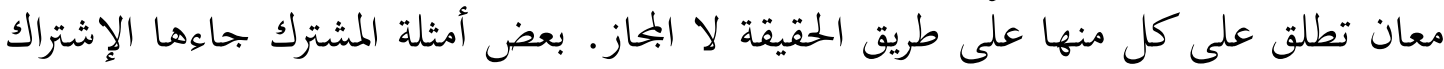
من اختلاف القبائل العربية فن إستعمالها.

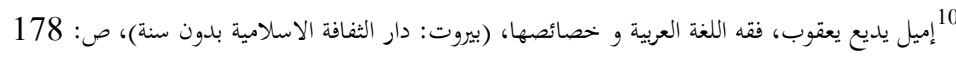

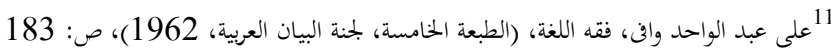

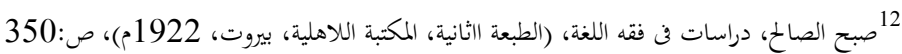
13

$$
\text { 14 إميل بديع يعقوب، فقه اللغة العربية و خصائصها ، ص: } 179
$$


و بعض أمثلته في الإسلام كلفظ "الخال" الذى يطلق على أخىى الأم، و على الشامة

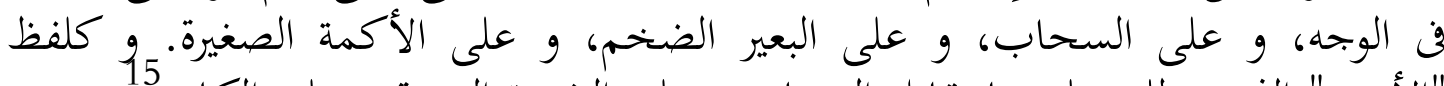

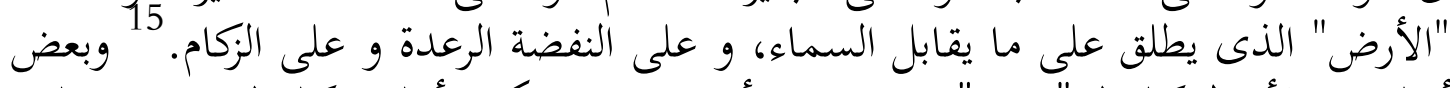

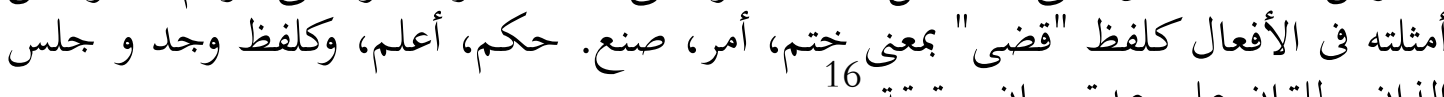
الذان يطلقان على عدة معان حقيقة. 16

\section{د. أهمية الإثتتراك اللغظى فحى اللغة العربية}

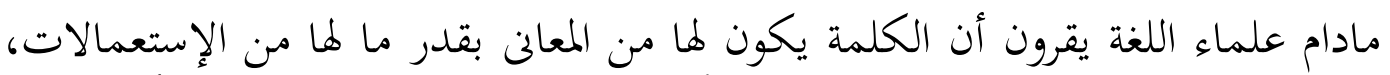

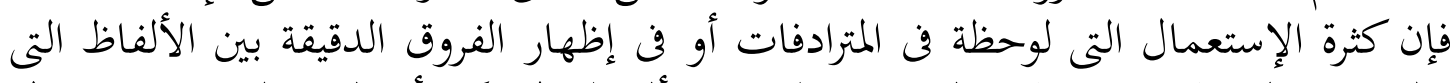

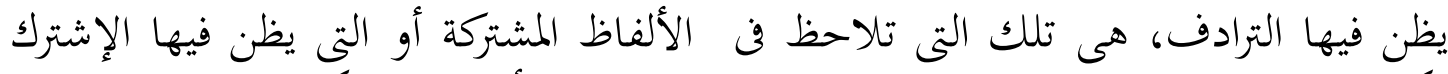

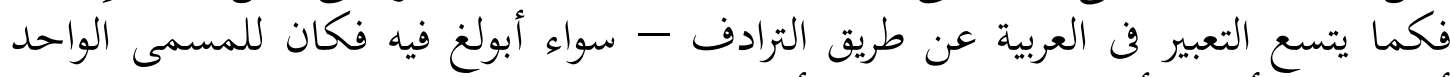

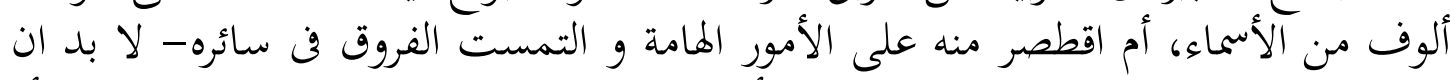

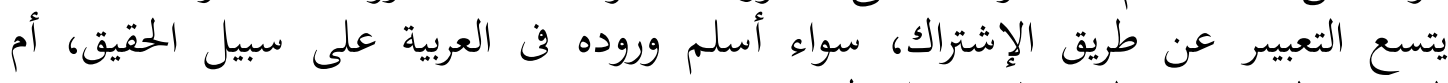
التمست له معان متطورة على سبير الئراك المحاز.

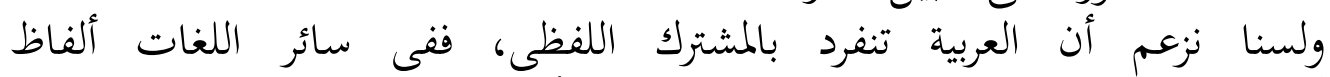

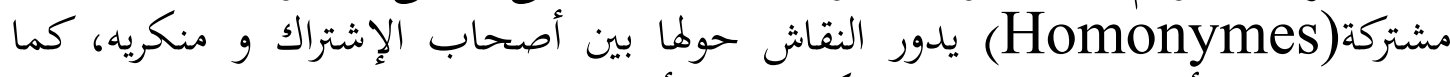

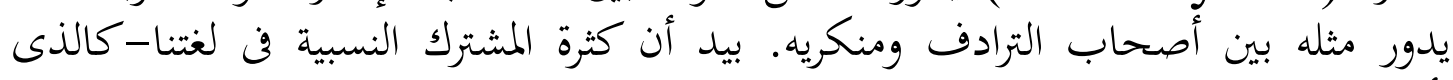

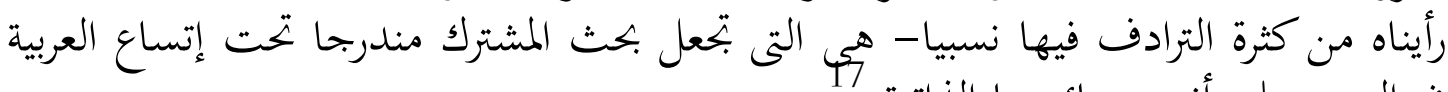
فن التعبير على أنه خصائصها الذاتية.

\section{هـ صيغة الإثتتراك اللغظى فحى اللغة العربية}

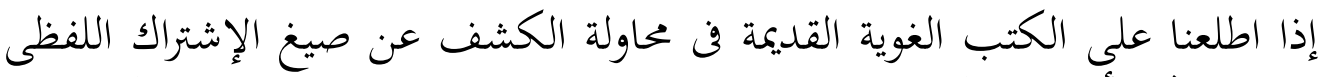

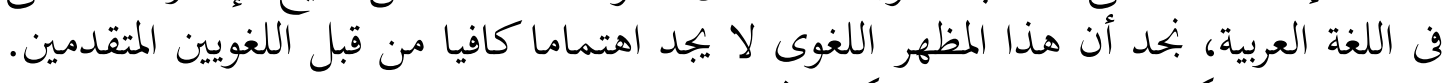

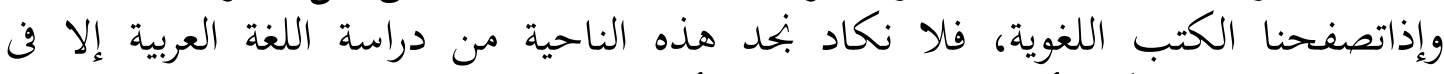

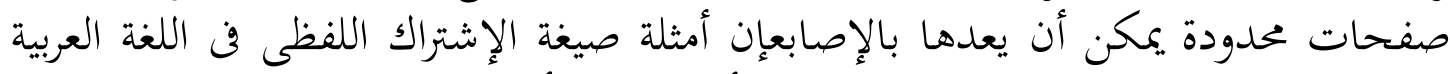

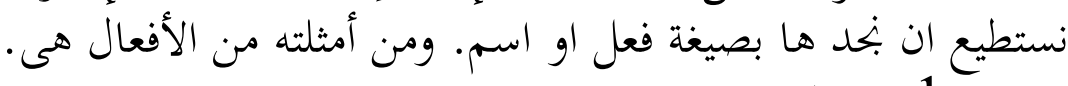

- بمعنى ختم، كقوله تعالى : "فلما قضينا عليه الموت". (سورة سباء:14) الإسراء: 23 آمعن)

15 15

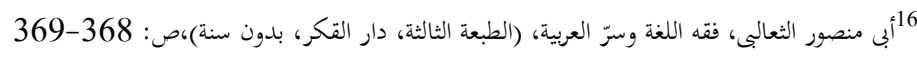

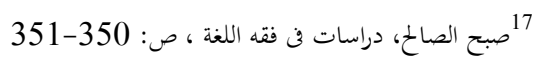


- بمعنى صنع كقوله تعالى" فاقضى ما انت قاض" أى فاصنع ما أنت

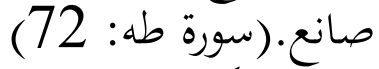
- بمعنى حكم، كقوله تعالى " وقضينا إلى بنى إسرائيل في الكتاب":

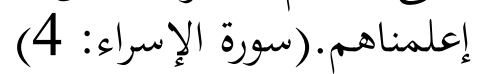
- ميقال للميت: قضى اذورا فرغ من الحياة -

- معمنى الصلاة معروفة، كقوله تعالى: "فصلّ لربّك وانحر" (سورة الكوثر: - مبعنى أدع لهم، كقوله تعالى :" وصل عليهم إن صلاتك سكن لهم

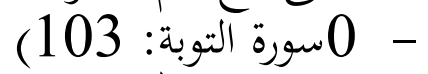

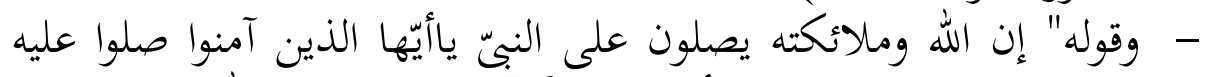

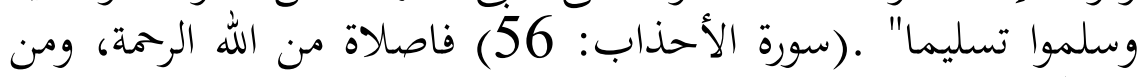
الملائكة الإستغفار، ومن المؤمنين الثناء و والدئاء

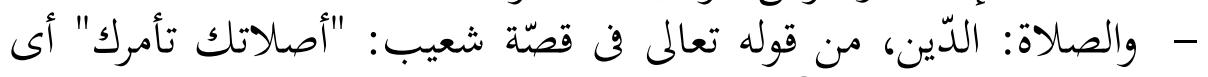
دينك. (سورة هود: 78) - والصلاة: كنائس اليهود، وفن القرآن: "لمدّمت صوامع و بيع وصلوات و مساجد". 18 -3

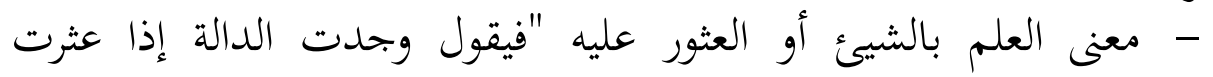

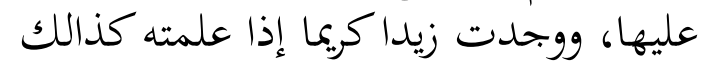

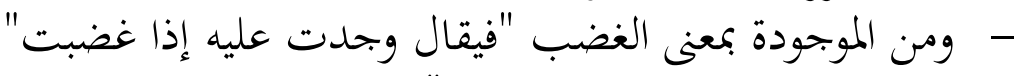

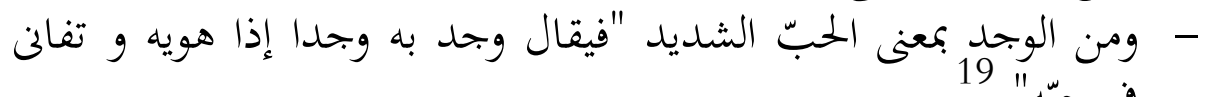

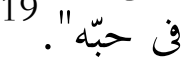

$$
\begin{aligned}
& \text { 4- - جلس: } \\
& \text { - مبعنى رجل طويل "لقد رأيت هذريا جلسا" }
\end{aligned}
$$

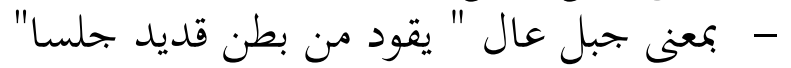

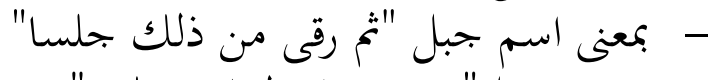

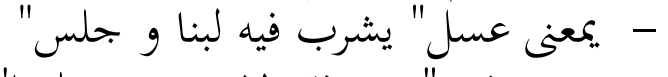

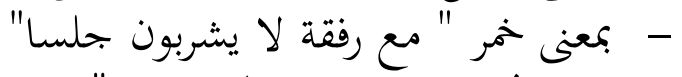

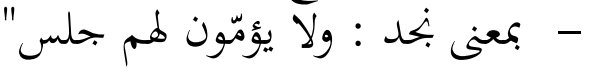

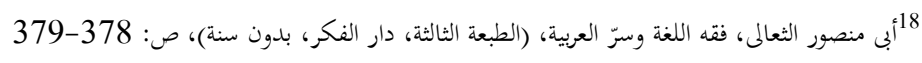

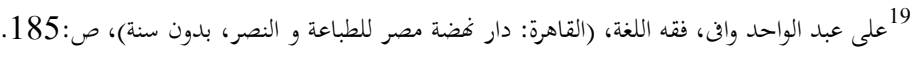


هذا الشعر كما ينشده الأنباري فن شرح المقامات وقد صلح لفظ "جلس" عنده

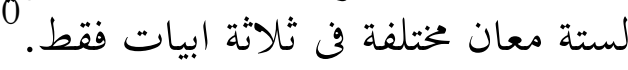

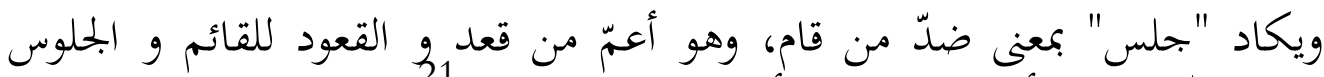

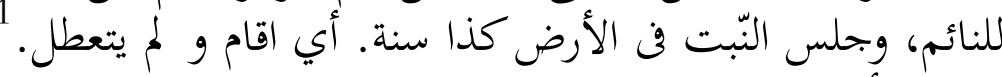

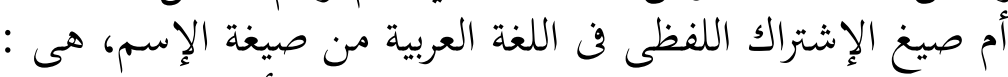
1-العين، بمعنى السحابة من قبل القبلة القبلة، مطر أيام لا يعلق، الإنى الدنانير، عين الرّكية،

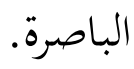

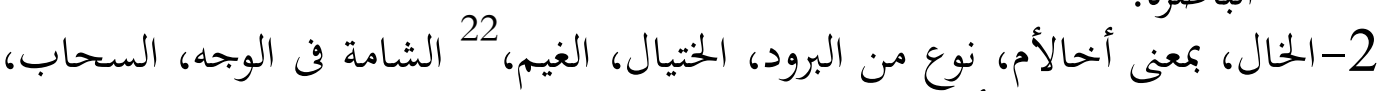

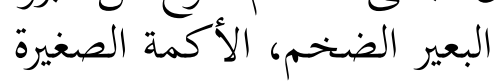

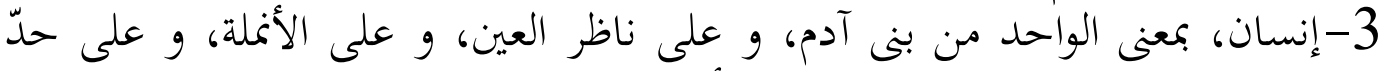

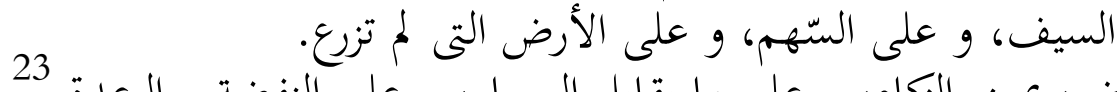

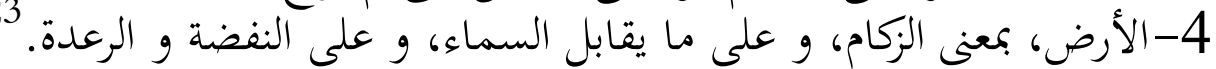

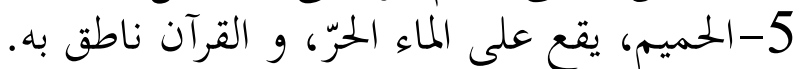

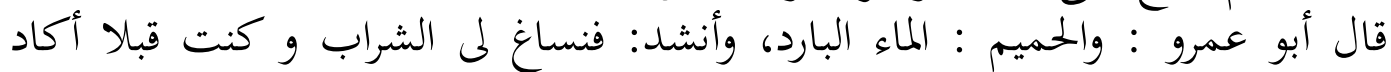

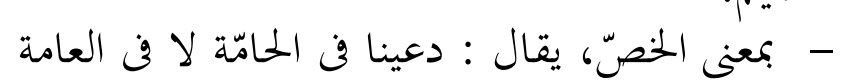

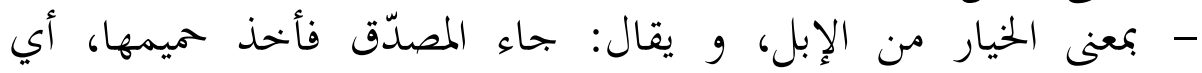
خيارها.

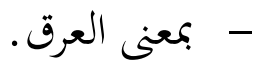

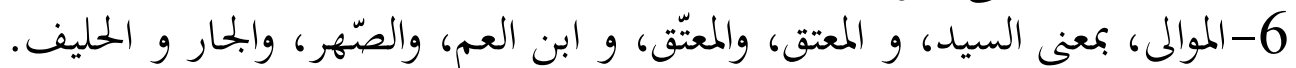

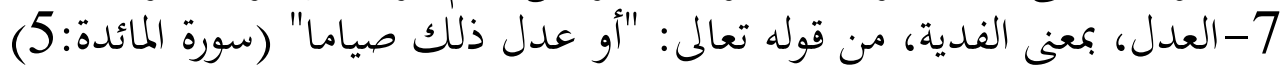

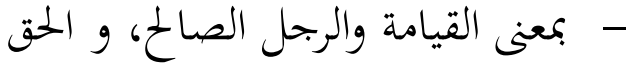

$$
\begin{aligned}
& \text { 8-المرض، المرض فن القلب : هو الفتور عن الحق الحق المقالة } \\
& \text { وفى البدن: فتور الأعضاء } \\
& \text { وفى العين: فتور النظر. فتور الاعضاء }
\end{aligned}
$$

هناك صيغة الإستخدام التى تطلق عليها بنوع من الإشتراك اللفظى و هى:

20 صبح الصالح، دراسات فن فقه اللغة، (التبعة الثانية، المكتبة الأهلية، بيروت، 1862م)،ص: 353-354.

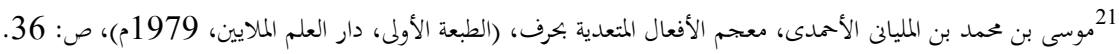

$$
\begin{aligned}
& \text { 232 } \\
& \text { 2323 على عبد الواحد وافى، فقه اللغة ، ص: } 183 .
\end{aligned}
$$

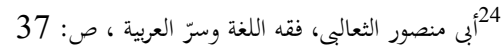


9-الشهر، كقوله تعالى: (فمن شهد منكم الشهرفليصمه)، بمعنى الهالال و أياكم

$$
\begin{aligned}
& \text { رمضان. (البقرة: 185) }
\end{aligned}
$$

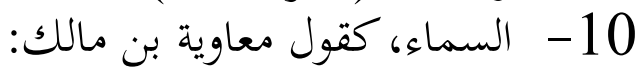

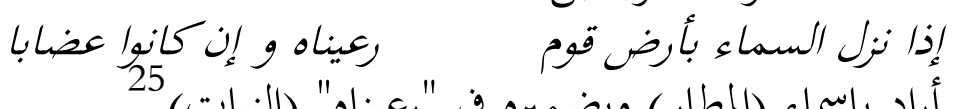

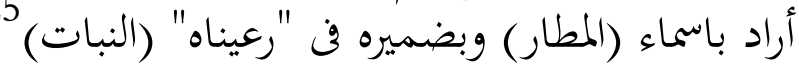

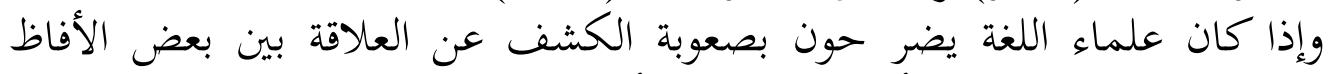

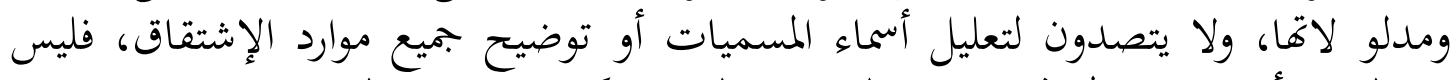

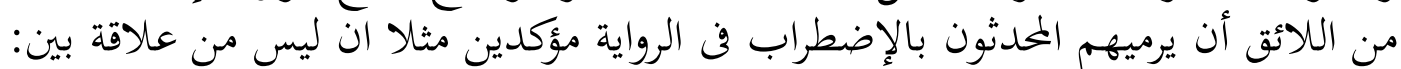

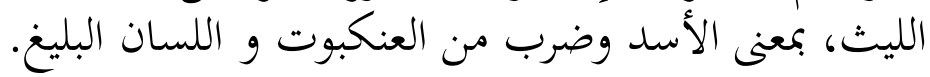

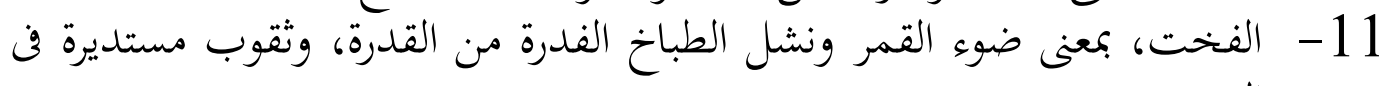
السقف.

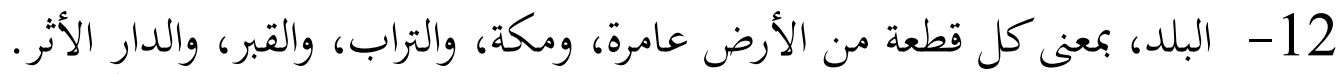

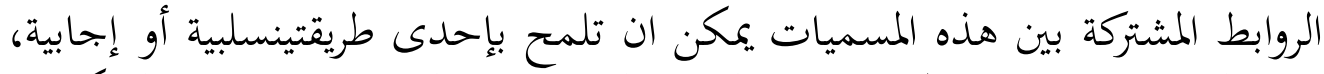

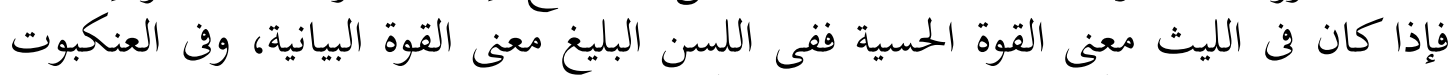

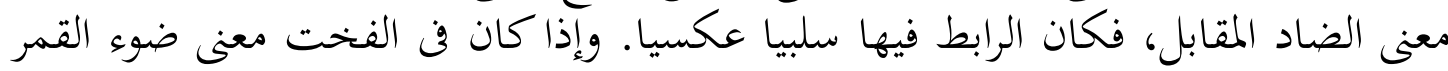

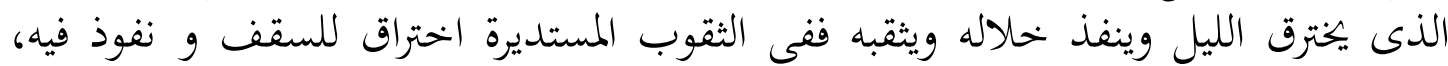

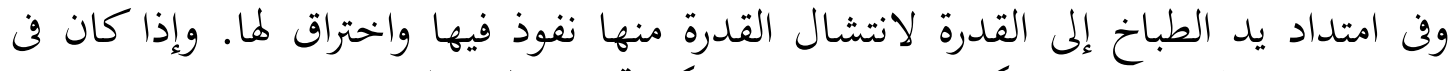

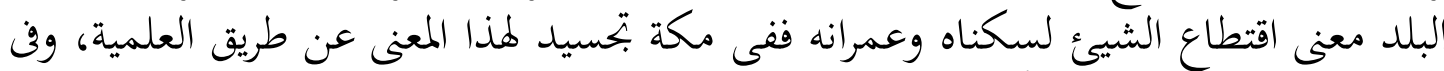

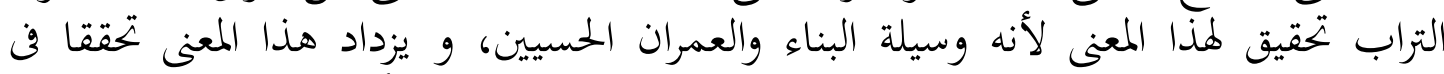

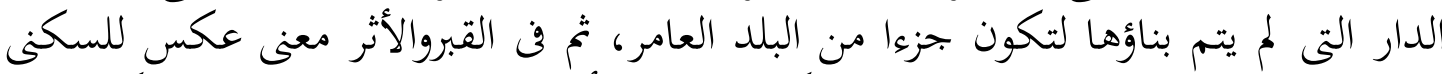

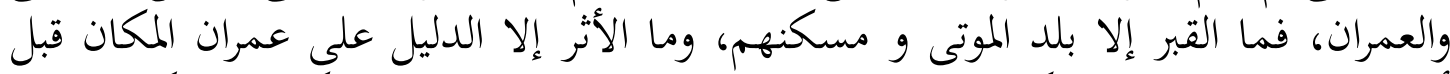

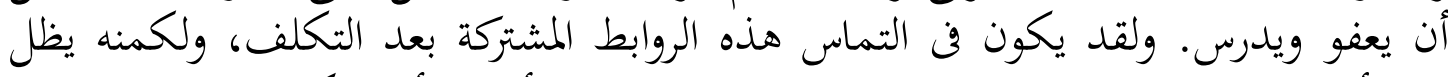

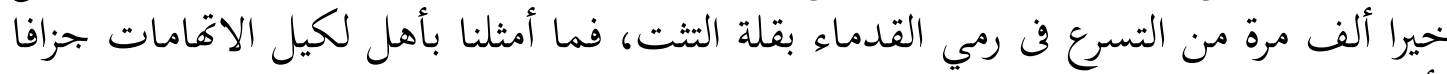

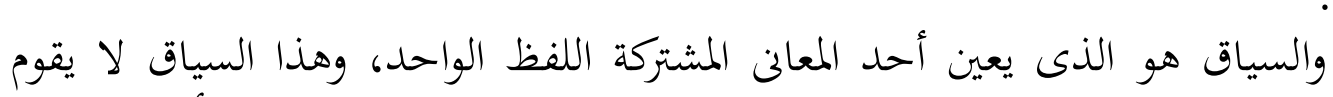

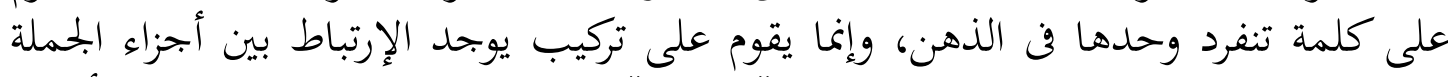

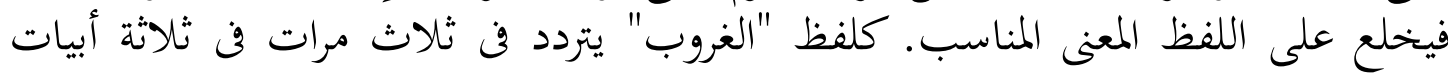

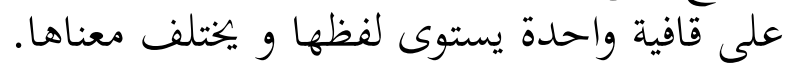

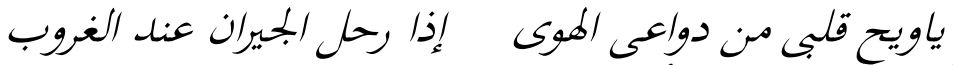

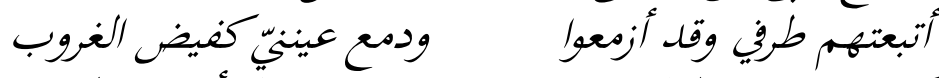

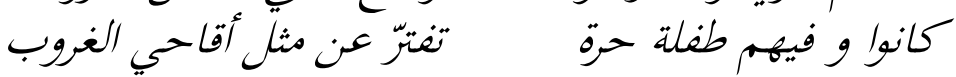

25 اممد الهلشمى، جواهر البلاغة فن المعانى و البديع، (الطبعة الثانية عشرة، مكتبة المداية، سورابايا، سنة 1960م)، ص: 364. 


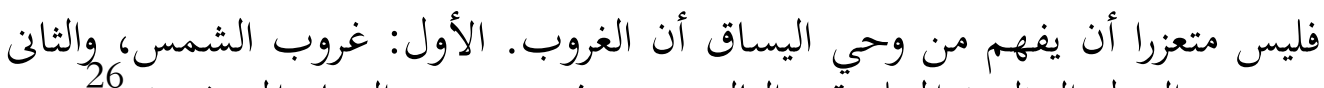

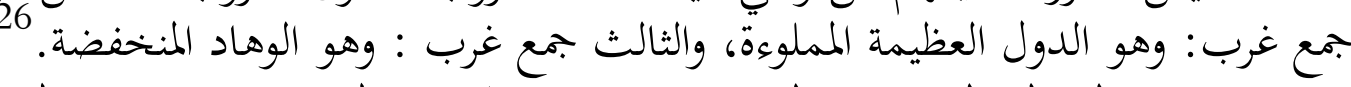

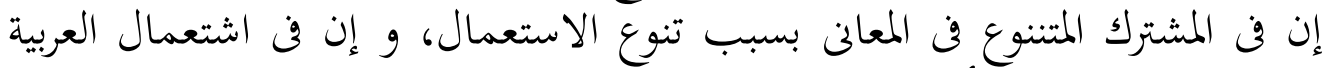

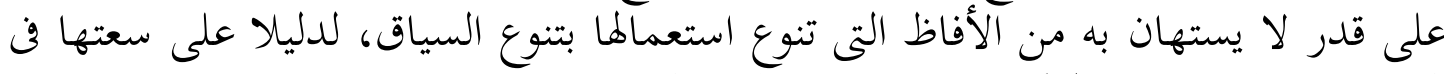
التعبير عن طريق الإشتراك كسعتها فيه عن طريق الأظ تنع الترادف.

و. الخحاصة

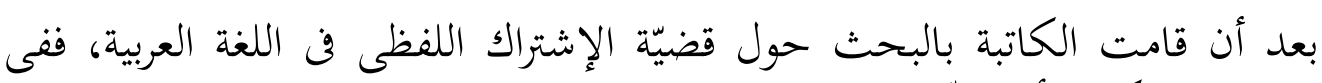

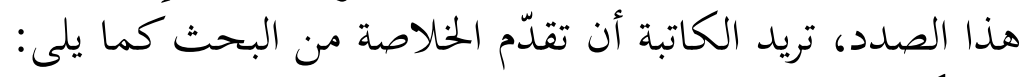

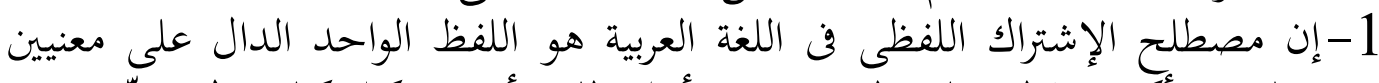

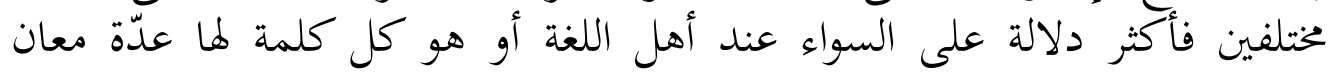
حقيقة غير بحازية.

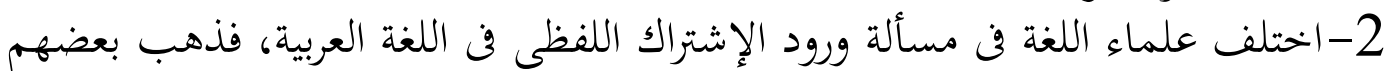

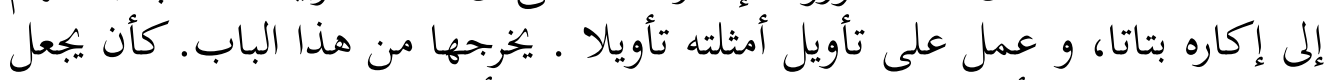

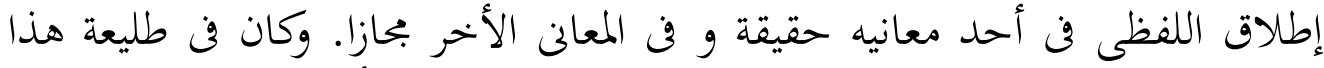

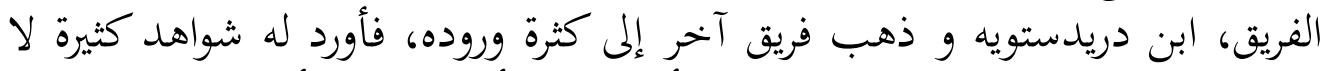

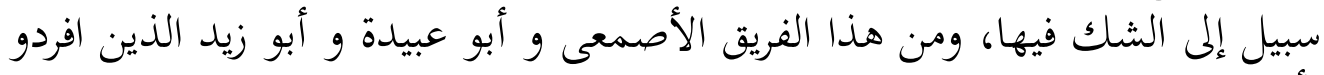
لأمثلته مؤلفات على فلى حدة.

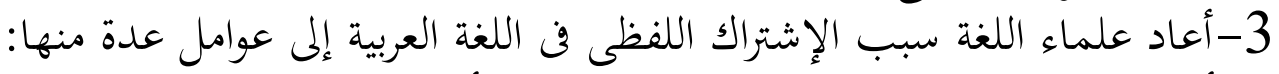

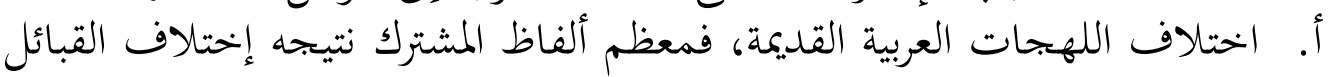

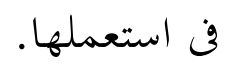
ب. التطور الصوتي الذى يطرأ على بعض أصوات اللفظ الأصلية من حذف أو زيادة

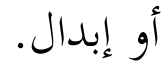

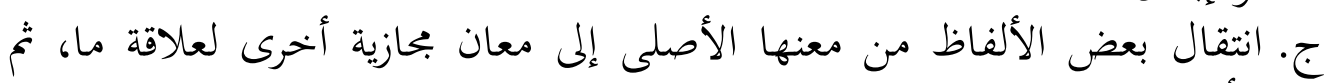

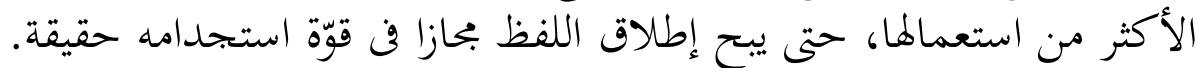

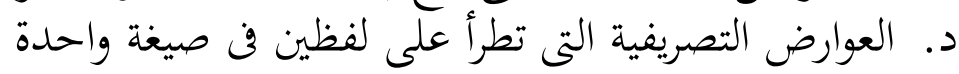

26 صبح الصالح،دراسات فن فقه اللغة ، ص: 356-358 


\section{المراجع}

أنيس، ابراهيم ، المعتجم الوسيط، الجزء الأول الطبعة الثالثة، دار المعارف بمصر، 1972

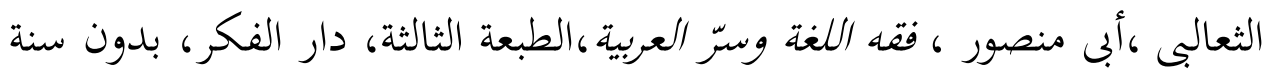

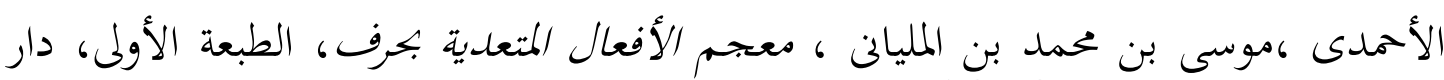

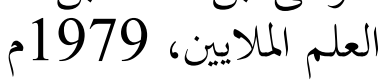

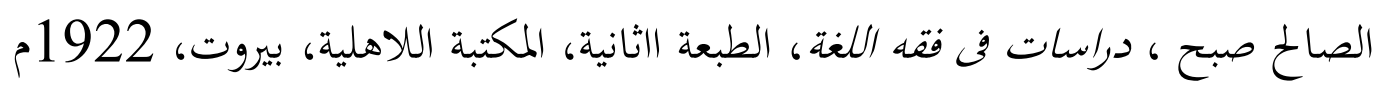

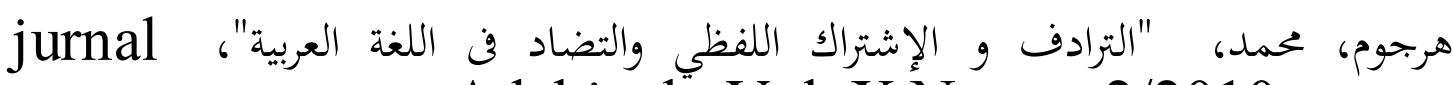
Adabiyah. Vol. X Nomor 2/2010.

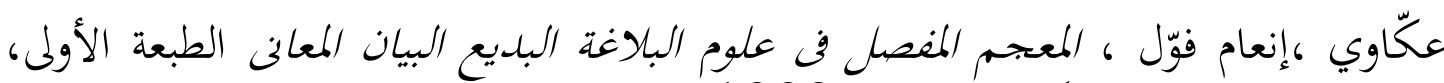

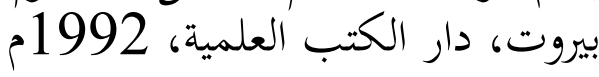

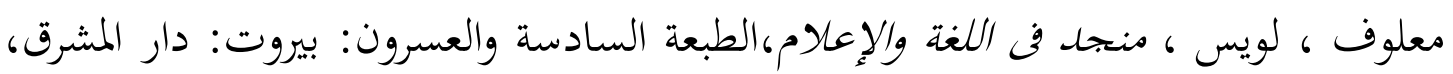
1986

وافى ،على عبد الواحد ، فقه اللغة، الطبعة الخامس : لجنة البيان العربى، 1962 م

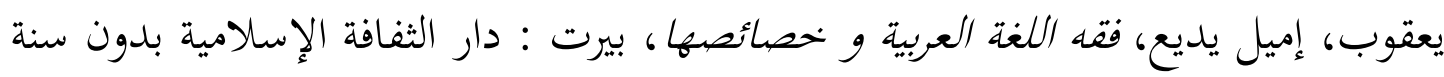

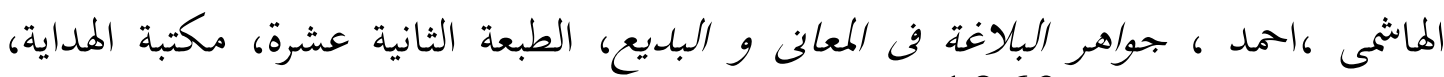

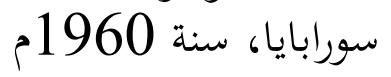


